\title{
The consensus paradox: Does deliberative agreement impede rational discourse?
}

Henrik Friberg-Fernros, PhD, University of Gothenburg, henrik.friberg-fernros@ pol.gu.se Johan Karlsson Schaffer, PhD, University of Oslo, j.k.schaffer@nchr.uio.no

Accepted for publication by Political Studies (forthcoming).

\section{Abstract}

This paper explores a tension in deliberative democratic theory. The tension consists in that deliberative opinion-formation ideally aims to reach consensus, while a consensus, once established, will likely impede the conditions for further rational public discourse. Hence, over time, deliberative democracy might risk undermining itself. While the tension is demonstrable in theory, we also suggest three cognitive and socio-psychological mechanisms by which consensus might hamper the rationality of public discourse: after an agreement, participants cease to develop new arguments, they tend to forget existing arguments, and their fear of deviating from the social norm promotes conformism. Existing research has largely neglected to study how consensus in decision-making affects future public deliberation. Our paper thus serves three purposes: To elaborate the consensus paradox in deliberative democratic theory, to open up a research agenda for examining the paradox empirically, and to assess the theoretical implications of the paradox.

Key-words: consensus, deliberative democracy, rationality, experiments, parliamentary discourse. 


\section{Introduction}

Over the past two decades, the idea of deliberative democracy has gained wide attention among political researchers as well as in the broader public. Theories of deliberative democracy assume that democratic processes of will- and opinion-formation aim to reach an informed, rational agreement among all affected parties and that public deliberation leads to better decisions than alternative procedures, since everyone gets to express their opinion on the matter and since different opinions are subject to open scrutiny, so that the better argument triumphs.

However, if deliberation aims to reach a rationally grounded consensual agreement, what happens to deliberation once that aim has been attained? Reaching a closure does not put an end to the need for further argument, but, we shall argue in this paper, it may impinge on the preconditions for future rational discourse. As such, closure implies that parties decrease or halt their deliberative activities, if only temporarily. The more such a closure approximates the ideal of consensus, however, the worse the conditions are likely to be for resuming deliberation at a later point in time. For instance, theorists emphasise that deliberative democracy is multiperspectival, expressing a diversity of views and opinions (Bohman 2003) and that disagreement is vital because it forces those who deliberate to form better reasoned opinions (Price, Cappella, and Nir 2002). But to the extent that deliberating parties successfully reach consensus, fewer opinions and less disagreement will be represented in their future deliberation. Thus, a consensus agreement might undermine the conditions for rational deliberation. This, we argue, represents a puzzling tension, or even a paradox, in deliberative democratic theory: How to reconcile, over time, the ideal of a rational consensual closure with the ideal of lively, ongoing public deliberation?

This paper proceeds in three steps: First, we detail why deliberative democratic theory may entail a tension between consensual closure and deliberative disagreement. We also suggest three causal mechanisms, grounded in cognitive and social psychology, to support the claim that actual public discourses could produce the paradoxical result we identify in deliberative 
democratic theory. Second, building on existing scholarship, we suggest research designs by which the consensus paradox could be studied empirically in both experiments and real-world public discourse, for instance in parliaments. Third, we reflect on what the consensus paradox implies for deliberative democratic theory and practice, and propose ways in which a deliberative procedure could seek to avoid becoming a victim of its own success.

\section{The contested role of consensus in deliberative democracy}

As deliberative democracy has matured as a research program, the ideal of consensus has been a central topic of debate (Bächtiger et al. 2010; Chambers 2003; Elstub 2010). Processoriented theories of deliberation emphasize rational consensus on validity claims as the ideally preferable outcome of public discourse. Joshua Cohen $(1998,199)$ stresses that deliberation should aim 'to arrive at a rationally motivated consensus,' arguing that 'public reasoning itself can help to reduce the diversity of politically relevant preferences because such preferences are shaped and even formed in the process of reasoning itself'. In his oft-cited statement of the ideal deliberative procedure, Cohen (1989) claims that '[o]utcomes are democratically legitimate if and only if they could be the object of free and reasoned agreement among equals'. Also, Jürgen Habermas $(1988 ; 1996)$ makes the ideal of a rational consensus the touchstone of his discursive theory of democracy. On this deliberative account, democratic decisions derive their legitimacy not simply from counting votes as expressions of preferences formed prior to political interaction, but from the sincere, reasoned unanimity among all affected parties. Participants reach such unanimity, or consensus, when they become convinced that a decision or a course of action is desirable through deliberation under conditions where the best argument wins.

Critics, however, have disputed consensus as an ideal outcome of deliberative procedures. Agonist and difference democrats, who accept few of the basic tenets of deliberative theory, have argued that consensus as an ideal of democratic interchange is both impossible and dangerous (Markell 1997). Consensus is unattainable or unlikely due to the facts of value pluralism in modern societies and the incommensurability of normative and epistemic 
frameworks (Valadez 2001). Moreover, consensus is politically perilous, because it violates this plurality and might serve to oppress or exclude certain interests, ideas and identities (Young 2001). For instance, Chantal Mouffe (1995) warns that seeking to eradicate all political antagonism while aiming for a universal rational consensus is 'the real threat to democracy.'

Taking on this challenge, theorists have sought to make the ideal of democratic deliberation more feasible under real circumstances, in societies characterised by social inequality and cultural diversity (Elstub 2010). Consequently, deliberative theory 'has moved away from a consensus-centered teleology' (Chambers 2003) to develop alternative notions of legitimate outcomes of deliberation. Even Habermas (1996, 165ff), for instance, concedes that where there is no hope of reaching a rational consensus, bargaining and compromise are acceptable outcomes, legitimate to the extent that they can be tested in moral discourse. Likewise, Bohman $(1996,89)$ suggests that where strong consensus is unattainable, parties may be able to reach plural agreement (or moral compromise), 'which merely requires continued cooperation in public deliberation, even with persistent disagreements', similar to Gutmann \& Thompson's $(1996,73)$ notion of deliberative disagreement, 'in which citizens continue to differ about basic moral principles even though they seek a resolution that is mutually justifiable.' More recently, Niemeyer \& Dryzek (2007) suggest meta-consensus, i.e., agreement on the issue at hand, but not necessarily on the actual outcome, as an ideal deliberative end, Moore \& O'Doherty (2012) develop a related notion of 'apparent consensus' as an acceptable outcome without normative unanimity, while Mansbridge et al (2010) suggest four forms of legitimate communicative agreement short of strong consensus.

Modifying the ideal of consensus in this way may seem to resolve our suggested paradox of consensus. For the paradox to be troubling to deliberative theory, consensus must be attainable and desirable. However, we shall argue that both 'strong consensus' and 'modified consensus' approaches to deliberative democracy should regard the consensus paradox as a normative problem and empirical possibility. 
Following Bächtiger et al (2010), we may consider consensus an ideal constitutive of deliberative processes. A common ground for theories of deliberative democracy is what Dennis Thompson $(2008,498)$ calls 'a reason-giving requirement': Everyone involved in the deliberative process is expected to justify the laws they would impose on one another by giving reasons. If you give reasons intended to justify your positions to others, you manifest an aim to persuade others (Larmore 1990, 347). Consequently, since everyone is required to justify their position to everyone else in the deliberative process, all participants aim to reach consensus based on their own arguments. In other words: To justify something is, implicitly, to raise a claim that consensus should be based on the arguments of which the justification consists. We need not believe literally 'that we are going to achieve consensus on some controversial matter' as Michael Neblo $(2007,536)$ puts it, 'but we have to act as if we could achieve consensus in order to make sense of rational deliberation as rational', for otherwise, '[i]f we are really just trafficking in our personal prejudices with no hope of reasonable persuasion, then deliberation hardly has a strong claim on us over standard models of aggregative democracy'. However, the reason-giving requirement implies not only that consensus should be based on your own arguments, but also that you should abandon your argument if you fail to demonstrate why the best available argument should be rejected. Argumentative rationality 'means that the participants in the discourse are open to be persuaded by the better argument' (Risse 2004, 294). To conclude, the reason-giving requirement implies an ideal of consensus, by stipulating that participants should adhere to the best available argument, regardless of whether it is theirs or somebody else's, and seek to persuade others to do the same.

This argument, however, might not impress proponents of deliberative democracy who, deeming the ideal of consensus to be unfeasible or unlikely in pluralistic societies, have sought to replace it with alternative notions of legitimate outcomes. Yet, even to these immanent critics, the consensus paradox remains a troubling possibility.

First, one should not overstate the incompatibility between the ideal of consensus and the reality of diversity. On the one hand, critics of consensus often seem to exaggerate the 
intractability of deep disagreement in pluralist societies. While cultural diversity may imply challenges for (deliberative) democracy, it is rarely reducible to irreconcilable moral values or incommensurable conceptual frameworks; rather, it entails multi-dimensional conflicts of a political kind that deliberative democracy aims to settle 'in ways that make it possible for one to reasonably accept their outcome.' (Bohman 2003, 96; cf. Deveaux 2003) On the other hand, some adherents of rational consensus seem to dispel it too far into ideal theory. For instance, on some Habermasian interpretations, 'no actually existing settlement can constitute a satisfactory embodiment of the regulative idea of agreement' (Markell 1997, 378f). But to deny that consensus could ever be acceptably achieved seems to rob the ideal of much of its normative force and heuristic utility (cf. Brady 2004).

Second, even agonist critics (e.g. Mouffe 2005, 31) concede that there is some role for consensus and agreement in a liberal democracy, even if it just results from a provisional stabilization of power. More importantly, many theorists within the deliberative programme, who recognize the impracticability of consensus, still seem to hold that deliberation should preferably produce normative agreement or moral compromise (cf. Deveaux 2003, 785). Such fall-back solutions imply striving for greater agreement. For instance, Mansbridge et al (2010, 68,70 ) claim that 'the goal at the outset of deliberation ought not necessarily to be a substantive consensus', but still suggest that deliberative processes end 'in a kind of consensus, that is, a genuine agreement among participants that the outcomes are right or fair.' Thus, these modified legitimate outcomes may be construed as non-ideal approximations of the abstract ideal, which still accept the view that consensus is ideally desirable but, given its impracticality, not necessary for democratic legitimacy.

Some of these difficulties may be resolved by conceiving of consensus as an ideal that can be realized to greater or lesser degrees in actual agreements (cf. Thompson 2008, 505). Actual outcomes may be ordered according to their deliberative legitimacy or desirability along a dimension, with modus vivendi or political compromise at one extreme, and at the other normative unanimity or rational consensus, with various conceptions of modified consensus 
someplace in between. This scalar conception may resonate with both the notion of consensus as a regulative ideal, the realization that it is variably attainable under real circumstances, and the openness to a variety of legitimate outcomes and second-order agreements. Regarding rational consensus as a matter of degree may also make the concept more useful for empirical study. And to the degree that consensus is achieved, the paradox potentially results: The more the outcome approaches consensus, the greater the risk of detrimental effects on subsequent deliberations.

\section{The paradox of consensus}

Given that deliberative democracy must ensure favourable conditions for rational public discourse even after reaching a closure, core claims in deliberative democratic theory generate seemingly contradictive implications. First, if deliberation among people who differ promotes rationality in collective decision-making, then we should expect the rationality-promoting effect of deliberation to end, or at least weaken, once the deliberative procedure stops. Second, to the extent that a deliberating group successfully reaches the aim of a full, rational consensus, its members will no longer be situated in the 'circumstances of deliberation', since 'some basic disagreement is necessary to create the problem that deliberative democracy is intended to solve' (Thompson 2008). Taken together, these assumptions lead to what we claim is a dilemma or a paradox of consensus in deliberative democratic theory: Rational, deliberative opinion formation aims at consensual agreement, but consensus as such will likely negatively affect the conditions for future rational public discourse.

In recent academic debates about consensus in deliberation, both normative and empirical scholars have focused on the process leading up to a collective decision, treating consensus as a prospective goal, but few have studied how an agreement approximating consensus, once established as a matter of fact, structures the conditions for future deliberation. This neglect is unfortunate, because reaching an agreement does not eliminate the need to argue in support of a policy position or a decision. 
Deliberative democratic theory underscores that agreements and decisions must constantly be subject to scrutiny and revision through deliberation (Benhabib 1994, 33). Agreements are perishables, made at specific points in time by specific parties, who may need to reconsider their agreement on specific issues as circumstances change. For one thing, new information might challenge the plausibility of the arguments supporting an agreement on a certain issue, and should trigger revisions of the arguments in order to maintain the rationality of the agreement. Hence, arguments once taken to be rational may lose their rationality over time, in light of new information, and thus, agreements can ever be considered finally settled. ${ }^{1}$ Likewise, agreements must be reconsidered as new persons - immigrants or new generations, for instance - become subject to authoritative decisions which they have not participated in making, following the oftcited all affected principle (Gutmann and Thompson 2000, 161). The consensus paradox implies that revisions, in light of new circumstances, may occur under less favourable conditions, if a previously established agreement has hampered or halted deliberation on these issues (cf. Deveaux 2003, 794).

Moreover, a consensus on one discrete issue might undermine the preconditions for rationality in other issues, for instance if an inference underlying a decision on one issue is relevant for decision making on another issue. Suppose that a parliament comes to a consensual agreement about prohibiting abortion due to the (assumed) human status of the embryo. The abortion agreement is not contested ex post, but as time goes by, another related issue is raised: Is it legally permissible to expend human embryos for research? Of course, the argument about the human status of the embryo is relevant for this issue too, but since the argument was not contested after the decision on abortion, the preconditions for a rational decision regarding human embryo research are not as good as they would have been, had the argument been contested. Consequently, the detrimental effects of consensus on rationality could be contagious across a range of related issues. 
The causal mechanisms: Stagnation, forgetfulness and conformism

So far, we have argued that there is a tension over time in deliberative democratic theory between, on the one hand, the ideal of rational consensus, and, on the other hand, the assumption that diversity in deliberation produces more rational decisions. In order to further substantiate this claim, we suggest three cognitive and socio-psychological mechanisms: Stagnation, forgetfulness and conformism.

1. Stagnation: Many theories of deliberation emphasise its potential to trigger processes of learning, moral development and preference transformation among participants (Doheny and O'Neill 2010) or that deliberation under conditions of diversity may generate new perspectives and novel reasons (Bohman 2006). If deliberation stalls, such generative processes also would seem to come to an end. Reaching a consensus results in a homogenous set of opinions, where the conditions for deliberating are presumably worse than where opinions are more heterogeneous (Ryfe 2005, 52). If disagreement fuels political debate, replacing it with consensus will likely cause deliberative activities to stagnate. Consequently, we should expect less improvement of rational public discourse compared to a situation with more disagreement, when the same issue is raised again.

2. Forgetfulness: Not only might a closure of deliberation lead parties to cease developing new arguments in favour of their preferred policy option, they will most likely forget existing ones, too. In the words of John Stuart Mill $(1991,59)$ :

even if the received opinion be not only true, but the whole truth; unless it is suffered to be, and actually is, vigorously and earnestly contested, it will, by most of those who receive it, be held in the manner of a prejudice, with little comprehension or feeling of its rational grounds.

That is, unless others continuously challenge your opinion, and unless you are compelled to defend it publicly, in order to convince an audience, you will have little reason to recall 
and refine the reasons in support of your view. In order for people to remember an argument, they need to spend time actually contemplating it, for instance by constructing counter-arguments for themselves (Goodin 2000; Goodin and Niemeyer 2003; Lupia 2002). This 'deliberation within', a process through which people try out and test arguments for themselves, will probably be more active if their view meets contestation. By contrast, absent such opposition, people who embrace the dominant view will be more likely to forget arguments (cf. Pingree 2006). And to the extent that people forget arguments, the conditions for a rational public discourse will also necessarily decline, so this mechanism might be self-reinforcing.

3. Conformism: Finally, people's fear for being different or deviant could explain why a massive consensus could threaten the rationality of public discourse. A series of classical experiments in social psychology demonstrate that people are strongly inclined to conform to what they take to be a prevailing norm. For instance, in Solomon Asch's (1951; cf. Larsen 1990; Schneider and Watkins 1996) conformity experiments, test subjects increasingly tended to provide incorrect answers to trivial, obvious factual questions, after confederates of the experiment unanimously had given wrong answers. On an aggregate level, this conformist inclination has been confirmed by partial empirical support for the so-called spiral of silence thesis. ${ }^{2}$ According to this thesis, people who deviate from what they take to be the majority view on a certain political issue tend to suppress their opinion, while those who think the majority agrees with them are more inclined to state their view publicly, which initiates a self-reinforcing spiral effect, as majority supporters speak out while minority supporters increasingly stay silent. Hence, this fear of deviating from what one takes to be the social norm may risk impinging on the free exchange of ideas and opinions, which is the very kernel of deliberation, and thus, it may also hamper the rationality of public discourse. Indeed, Gerry Mackie $(2006,285)$ calls this human inclination not to deviate from prevailing norms a 'non-rational conformism'. 
As such, argumentative stagnation, forgetfulness and conformism represent three plausible causal mechanisms explaining why a massive consensus might impede the rationality of future public discourses. While these mechanisms probably interact, they are analytically distinct. The first mechanism, stagnation, reflects assumptions about the value of deliberation within deliberative theory: If one believes that deliberation promotes rationality, then, as a matter of consistency, one should also believe that less deliberation, which logically follows after consensual closure, would negatively affect the rationality of public discourse. In contrast, the two other mechanisms, forgetfulness and conformism, are based on cognitive and social psychology and are not derived exclusively from within deliberative democratic theory. They might therefore seem less consequential for the theory, but to the extent that they occur in real deliberation, the effects may be more dramatic, since they not only weaken the improvement of arguments (as the mechanism of stagnations does), but also undermine the use of existing arguments. If mechanisms of forgetfulness and conformism are triggered by consensus, people will forget the reasons that justified the consensual agreement, or fear to challenge them critically, which means that further deliberation not only fails to improve the rationality of public discourse, but also that consensus decreases rationality over time.

Our argument about the consensus paradox innovatively departs from two types of previous critiques of deliberative theory because we offer an endogenous explanation of the detrimental effects of consensus-oriented deliberation. First, one strand of criticism has suggested that consensus-oriented deliberation may serve ideological purposes by reproducing pre-existing social inequality, marginalization and hierarchies. 'When hegemonic discourse operates', writes Young $(2001,685)$, 'parties to deliberation may agree on premises ... yet the premises and terms of the account mask the reproduction of power and injustice.' Sanders $(1997,362)$ similarly suggests that 'where there are gross inequities in power and status, calling for compromise may be perilously close to suppressing the challenging perspectives of marginalized groups.' Certainly, disparities in wealth, power and status may severely distort deliberation. Our argument, however, relies neither on sociological assumptions about external, 
social conditions nor on a notion of false consent, in order to explain why consensus could hamper rational dialogue, and therefore, from the point of view of deliberative theory, it seems more parsimonious and challenging.

A second strand of criticism questions deliberative democratic theory's assumption that public deliberation produces epistemically better outcomes than non-deliberative procedures. These critics argue that while groups sometimes outperform individuals and while groups of lay persons sometimes outperform individual experts in producing good epistemic outcomes, deliberation within groups will not necessarily make them collectively smarter. To the contrary, Cass Sunstein (2005) argues that group deliberation can serve to polarise opinions among group members in a way that does not improve the rationality of their collective opinion-formation. Likewise, James Surowiecki (2005) warns that too much communication can make groups less intelligent, as it makes members less independent and furthers groupthink, so that the group as a whole does not take advantage of the comparative advantages of individual group members. Outright rejecting deliberation, Hibbing \& Theiss-Morse $(2002,191)$ claim that it 'can lead to worse decisions than would have occurred if no deliberation had taken place'.

However, these doubts about public deliberation have limited implications for our present purposes. First, the sceptics' warnings about the negative effects of deliberation are in line with our argument, as we hypothesise that discord and heterogeneity among deliberants imply comparative advantages in terms of rationality in public deliberation. Second, empirical research on deliberation tends actually to support the deliberative democratic claim about the epistemic effects of deliberation, although this conclusion is hedged with reservations (Gastil and Dillard 1999; Ryfe 2005). Hence, on empirical grounds, we can assume that increased deliberation will improve the rationality of public political discourse. Third, given that the consensus paradox can be deduced from assumptions in deliberative theory, its problematic theoretical implications for deliberative democracy do not depend on whether deliberation actually promotes rationality. 
To conclude, we believe that our argument about the consensus paradox represents a novel, original issue in deliberative theory, as it points to a tension between core assumptions which becomes visible once we model consensus-oriented deliberation as an iterated process.

\section{The consensus paradox and empirical research}

The consensus paradox is not just a theoretical puzzle, but suggests that making agreements in consensus will affect the rationality of subsequent public discourse - a testable, empirical proposition. In this section, we survey existing research and suggest methods by which to assess whether the consensus paradox actually occurs in small-group experiments as well as in real-world deliberative situations.

Given how central the ideal of consensus is for deliberation and decision making, it features in plenty of empirical studies on a micro level (for an overview, see Kerr and Tindale 2004). Using experimental designs as well as natural groups, this line of research examines deliberation and decision-making in small groups (for an overview, see Gastil 2010) and typically asks how the procedural requirement to make decisions consensually impacts on deliberation and decision-making. ${ }^{3}$ Several studies support our hypothesis that consensus negatively affects rationality (see for example Postmes, Spears, and Cihangir 2001; Schweiger, Sandberg, and Ragan 1986; Tung 1993). In his meta-analysis of this literature, Charles Schwenk $(1990,161)$ states that '[a] large body of research demonstrates that conflict can improve decision quality'. However, by focusing exclusively on consensus as a prospective end-state of deliberation, this line of empirical research on how consensus as a goal affects deliberation only includes the process leading up to a decision, but not in the deliberative sequence following after an agreement. Here, we see fruitful opportunities for exploring whether a consensus agreement in itself influences the rationality of subsequent deliberation, for instance by the mechanisms of stagnation, forgetfulness and conformism, when a group meets after some time to discuss the same issue again. 
A related line of research on a macro level examines how the degree of polarisation on a political issue affects opinion formation in real-world policy debates. In their study of parliamentary debates, Steiner et al (2004) construct a Discourse Quality Index, which measures, among other things, how well members of parliament justify and give reasons for their policy positions (cf. Bächtiger et al. 2005; Steenbergen et al. 2003). According to Steiner's et al results, parliamentarians give better reasons for their positions on issues that are nonpolarised than they do on issues where opinions are strongly polarised. Explaining this result, Steiner et al argue that parliamentary politicians are more oriented towards pragmatic cooperation on non-polarised issues, which in turn forces them to give more thorough reasons for their positions.

Our consensus paradox thesis may seem to be contradicted by Steiner's et al empirical finding that discourse quality increases when issues are less polarised. However, there are important differences: First, Steiner et al study the quality of deliberation leading up to a decision, while our argument concerns the rational quality of the opinion-formation processes that follow after a deliberative agreement, and thus their empirical results, strictly speaking, do not pertain to the paradox. Second, our explanatory model is compatible with theirs, since we do not claim that the preconditions for rational opinion-formation improve the more polarised the debate. For instance, politicians have only weak incentives to justify publicly their positions on strongly polarised issues, as they have little reason to believe that they will be able to convince their opponents on such issues. Moreover, the distinction between polarised and non-polarised issues is not exhaustive. A high degree of unanimity, not to be confused with non-polarisation, may undermine the preconditions for rational deliberation. What happens when the nonpolarised condition in a debate - which still can accommodate contradictory opinions transforms into unanimity? Theoretically, it seems improbable that the positive effect upon political debates remains. ${ }^{4}$

Hence, while existing empirical studies of deliberation provide important pieces to our puzzle, the consensus paradox as such has not yet been tested in empirical research. In the 
following, we suggest methods by which to test whether the paradox can be observed in smallgroup experiments as well as in real-world deliberative processes, such as parliamentary debates.

\section{Testing the paradox in experiments and real-world deliberation}

Many studies of deliberation in general and consensus more specifically are based on small group discussions in experimental settings (Mendelberg 2002; Renz 2006). These studies are marred with an important limitation: the outcome of deliberation in such settings usually makes no real practical difference for the parties involved. And sometimes, as in Fishkin's oftcited deliberative experiments, the participants are not even asked to make a collective decision at all (Thompson 2008, 503). Still, an experimental research design provides crucial tools for testing the hypothesis that consensus negatively affects rationality. By simulating deliberation on a set of policy issues in small-group settings over time and by manipulating circumstances of importance for the emergence of consensus, experiments allow for drawing more robust conclusions about causality.

The obvious alternative to experiments is to study whether the consensus paradox occurs in real-world public deliberation, for instance in parliamentary assemblies. While discussion and debate in parliaments and similar forums may seem distant from the ideals of deliberative discourse, they offer opportunities to study deliberation under circumstances where its outcome really matters, in contrast to the deliberative outcome in experimental settings. Moreover, operating with a low threshold, one may regard deliberation as any cognitive process where actors form and express opinions through argumentation (Habermas 1996; Wessler 2008; Simon and Xenos 2000). Additionally, deliberation can be more or less complete (Fishkin 1997, 41; cf. Bächtiger et al. 2010); that is, opinions can be more or less formed and expressed through argumentation. Hence, parliamentary arenas contain elements of deliberation, even as they are more or less far away from the ideals of deliberative democratic theory. In real political life, deliberation is always imperfect (Grimes 2008; Gastil 2006). 


\section{Specifying the consensus paradox hypotheses}

In order to derive falsifiable mid-range propositions from our general theoretical claim (cf. Mutz 2008), we propose a weak and a strong version of the consensus paradox hypothesis. The weak hypothesis only expects the mechanism of stagnation to set in, whereas the strong hypothesis additionally assumes forgetfulness and/or conformism to be operative.

- $\quad$ H1 (weak): The more an agreement on a policy issue approximates consensus, the less will subsequent public discourse on that issue improve rationality.

- $\quad \mathrm{H} 2$ (strong): The more an agreement on a policy issue approximates consensus, the less rational will subsequent public discourse on that issue be.

The weak hypothesis does not imply that a highly consensual agreement decreases the rationality of subsequent public discourse, only that it hampers the development of new arguments compared to a situation where the prior agreement was less consensual. After having reached a highly consensual agreement, participants cease developing better arguments or elaborating the ones they already have in subsequent debates - they just repeat existing arguments. Thus, renewed deliberation preserves but does not improve the rational quality of public discourse. Vice versa, on issues where the prior agreement was less consensual, we would expect participants to be more innovative in developing better arguments and elaborating existing arguments.

To test the weak hypothesis in parliamentary arenas, we propose a research design based on the logic of minimal variation, comparing cases of public policy debates that differ only with regard to the level of consensual agreement over time. The hypothesis would be confirmed to the extent that the result demonstrates that renewed deliberation leads to less improvement of rationality in cases with highly more consensual agreement than in cases with less consensual agreement. 
The strong hypothesis more boldly states that consensus decreases rationality over time. That is, after a highly consensual agreement, we expect participants to forget arguments and knowledge about the issue, and/or to conform to the previously established consensual norm for non-rational reasons, in subsequent public discourse on the same issue. Conversely, on issues where the previous agreement was less consensual, we would expect participants to remember more arguments and knowledge about the issue at stake, and be more inclined to speak out if they dissent from the prior agreement.

To test the strong hypothesis, we propose a longitudinal design comparing the rational quality of public discourse over time on policy issues where the degree of consensual agreement has varied. The hypothesis would be corroborated if the result demonstrates that the rationality of public discourse decreases on issues where a prior agreement was highly consensual, and vice versa. In order to make the result more robust, the longitudinal design could be complemented with a broader sample of public discourses on policy issues exhibiting varying degrees of consensual agreement over time, across different institutional settings, in order to control for effects of, for example, electoral system, party system and political culture. Additionally, sampling cases from deliberative arenas other than parliaments could help corroborating the results, provided the degree of consensual agreement varies over time.

Both hypotheses could also be tested by experiments in small-groups deliberating on policy issues at two points in time. By distributing participants to groups on the basis of their attitude to a certain policy issue at the first session, we can assure variation in the degrees of opinion homogeneity between groups. By assigning each group to discuss and reach a collective decision on the policy issue and then to justify their decision in writing, the necessary data for analysing the rationality of the group's decision will be provided. Adding some information of relevance for the decisions in the first session, the procedure will be repeated at a second session. Consequently, this design allows for examining whether the strength of agreement in the first session affected the rationality of discussions in the second session, and thereby tests the weak as well as the strong hypothesis. 
While the repeated-measures design described above may discriminate between stagnation and forgetfulness, it may reveal less on the role of conformity. Therefore, it needs to be complemented by an experimental design in which the degree of conformity as an independent variable is manipulated. This can be done by assigning the role of a devil's advocate to one or more group members in half of the groups (Kerr and Tindale 2004; Schwenk and Valacich 1994). This design can straightforwardly test whether disagreement in the discussions promotes rationality, and thus whether the weak hypothesis holds true.

\section{Assessing outcome rationality}

Rationality is a complex concept used in several ways in deliberation research: it may, roughly, refer to (1) the cognitive capacity of individuals (Goodin 2000) or collective persons (Pettit 2001) to use reason in forming a judgment or decision; (2) the norms regulating deliberative procedures or the logics governing different modes of social interaction (Bohman 1998; Blau 2011); or (3) the epistemic quality of the collective decisions or judgments resulting from deliberation (Cooke 2000, 952). Here, we focus on devising empirical tests for outcome rationality (3) following a mixed-methods approach.

According to our hypotheses, consensus impedes the rationality of public discourse by hampering the development of new arguments and/or undermining the quality of existing ones. Hence, we need to specify how to measure the degree to which deliberants offer reasons for their positions. Generally, one could measure the expected effects of the mechanisms behind our hypotheses - i.e., stagnation, forgetfulness and conformism - quantitatively or qualitatively, since we expect reasons to become fewer and arguments to become weaker in the shadow of consensus.

The existing literature suggests various ways to quantitatively measure individual or collective reason-giving in different contexts, but need tweaking to fit the diachronic logic of our argument. Employing the toolset of argumentation analysis, one could map the arguments (cf. Nanz and Steffek 2005) and then use numerical measures to test (H2) whether deliberants 
present fewer reasons when they reopen an issue some time after a consensus decision, or, respectively, (H1) whether they present fewer reasons on issues more dominated by consensual agreement than on issues less so dominated. One example is the 'level of justification' (Steiner et al. 2004), which measures the number of reasons speakers offer in support of their position. This measure may give a crude indicator of whether the mechanisms are at work: Ceteris paribus, i.e., holding constant the quality and consistency of the reasons, a position would seem weaker the fewer reasons that support it. A second example, the 'argument repertoire' (Cappella, Price, and Nir 2002), includes both the number of reasons for a position and the number of reasons for the opposite position. Adapted for collective reasoning, 'argument repertoire' may allow testing our hypotheses, as a decline in stated contra reasons might indicate even stronger the causal mechanisms at work. These two examples, then, illustrate established measures of discourse quality that could be adapted for testing our hypotheses. Obviously, all such tests should be cautiously interpreted and complemented with qualitative analysis.

To test whether the mechanisms also undermine the quality of arguments on an issue involves another host of difficulties. According to common argumentation theory, the quality of an argument is determined by the truth of the premises and the validity of the inference (Blair 2012), and the consensus paradox could affect both. Given the problems involved in assessing empirically the plausibility of both normative and factual premises, we suggest that focusing on validity provides a sufficient and economical way to test the hypotheses (cf. Bächtiger et al. 2010, 41; Steenbergen et al. 2003, 25). In general, it is difficult to assess the truth of the premises of political arguments, and the result is bound to be controversial. Moreover, testing our hypotheses by assessing truth turns out to be especially problematic, since external factors, such as the general availability of information, are likely to influence variation within and across contexts. By contrast, the validity of the inferences can be determined independently of external criteria of truth or goodness. Besides, examining validity is sufficient for examining our 
hypotheses: If consensus undermines the quality of existing arguments or hampers the development of new arguments, the validity of inferences would likely be impaired.

How to measure the validity of inferences? We suggest that drawing on argumentation theory may advance methods for assessing the quality of arguments in public deliberation. In informal logic, validity means that the premises should be relevant to or support the conclusion (Groarke 1996; Govier 1995), but there is no distinct, general theory of how strong this support should be in order to be sufficient. Existing quantitative measures of deliberation quality (e.g. Steiner et al. 2004, 171ff; Cappella, Price, and Nir 2002, 77) leave coders some discretion in contextually interpreting the relevance of reasons. A stricter procedure for assessing the adequacy of support could employ a three-tiered test proposed by Anthony Blair $(2012,192)$. First, one looks for deductively valid inferences, i.e., where the premises entail the conclusion. Second, if the argument is not deductively valid, one asks whether the argument might be inductively strong, i.e., whether the conclusion is probably true given the premises. Third, if the argument fails the two first tests, one asks 'whether in the circumstances the grounds support the proposition at issue on the basis of some other kind of rule of inference'. An example is the presumptive warrant (Walton 1996), where an argument scheme (e.g., argument from analogy, authority or slippery slope) shifts the burden of proof to the interlocutor, which can be assessed by running through a set of critical questions for each type of scheme. ${ }^{5}$ An argument which fails these three tests could reasonably be classified as inadequately supported by reasons. This method requires further elaboration, and is useful only if it ceteris paribus delivers more reliable results than the less intricate approaches. Still, sufficiency is inescapably contextual (Pinto 2001, 27), which calls for a transparent reconstruction of arguments in order to ensure intersubjectivity.

Is outcome rationality too narrow an operationalization of the broad concept of rationality in deliberative theory? Obviously, our operationalization does not exhaust all aspects of rationality and reasonableness. However, it reflects the notion of discursive rationality (Steenbergen et al. 2003) and deliberative democracy's defining conceptual criterion of 
legitimacy as mutual justification, i.e, 'presenting and responding to reasons intended to justify a political decision' (Thompson 2008, 504). While the model we present in this paper is confined to the epistemic claim in deliberative democratic theory, we also see interesting possibilities for exploring ex post effects of consensus for sustaining the educative or transformative claims, i.e., the idea that democratic deliberation improves the participants' moral, practical or intellectual qualities (Cooke 2000, 948) or induces them to transcend their private interests and identities.

\section{Theoretical implications of the consensus paradox}

If, as we have argued, deliberative democratic theory harbours a consensus paradox, so that the better parties approach consensus in their agreement, the worse the conditions over time for rational deliberation, what should be done? Could the dilemma be avoided or could its effects be mitigated?

The consensus paradox is a matter of theoretical implication in deliberative democratic theory. Combined, the two assumptions that disagreement in deliberation promotes rationality in decisions and that deliberation should aim for consensus agreements seem to imply that rationality may be affected negatively to the degree that consensus is reached. This theoretical conundrum may be worthwhile to address in its own right, regardless of whether empirical studies, such as those we have suggested above, would corroborate the hypotheses that consensus makes future deliberation less rational. Yet, if one wishes to address the theoretical puzzle, one should still take such empirical studies into account, because, first, even if the results would support the hypotheses, the magnitude of detrimental effects of consensus on rationality is still important to consider in a theoretical approach. Second, and more fundamentally, empirical studies could falsify the paradox altogether since the seemingly conflicting assumptions in deliberative theory, which lead to the consensus paradox, may be false. 
A negative empirical result, falsifying both the strong and the weak hypothesis on the consensus paradox, might seem unproblematic for deliberative theory. However, a negative result might actually be quite troubling. The consensus paradox builds on a core claim in deliberative theory: That the quality of public opinion benefits from having a diverse and lively deliberative debate. However, if the cessation of deliberation has no effect on the rationality of public discourse, we need to reconsider a major empirical claim in deliberative democratic theory: that on-going public deliberation makes a difference. A negative result might thus seem to resonate with the critique against deliberation raised by sceptics such as Sunstein (2005), Surowiecki (2005) and Hibbing \& Theiss-Morse (2002). Of course, one could still favour deliberation on grounds other than its epistemic benefits.

However, even without empirical support, the theoretical puzzle of the consensus paradox still needs to be resolved, for two reasons. First, empirical studies of deliberation have tended to generate findings 'mixed or inconclusive', mainly because 'the success or failure of deliberation depends so much on its context (Thompson 2008, 499). Consequently, it may be wise not to reject the value of deliberation based on empirical studies of the consensus paradox alone. Second, as we argue above, the consensus paradox exists in deliberative theory as a matter of implication, which means that the paradox is ontologically independent of empirical results. Hence, while empirical studies supporting the claim that consensus has a negative impact on rationality seem more urgent for deliberative democracy, the paradox's theoretical implications merit consideration in their own right.

A positive result, confirming that consensus negatively influences rationality in actual political debates, yields different theoretical implications for deliberative democratic theory. Dennis Thompson gives a sort of value pluralist defence of deliberative democracy, in arguing that we should recognise that the elements deliberative democracy seeks to promote may sometimes conflict with each other, in theory as in practice, and 'that we have to make hard choices among them' (Thompson 2008, 511). The consensus paradox points to such a potential conflict between fundamental values in deliberative democratic theory, but also in actual 
deliberative practice. Following existing approaches in deliberative research, one could seek to resolve the conflict by either, first, abandoning the ideal of consensus, and move in the direction of agonistic democracy, where argumentation does not serve to reconcile but to recognize conflicting interests and identities. Alternatively, second, one could seek to modify consensus into a more abstract ideal, and seek fall-back standards of legitimate decision-making under non-ideal conditions. A third strategy would, instead, accept the paradox, but seek to mitigate its effects, by incorporating into deliberative democratic theory practices and institutions which reduce the risk, after an agreement, that people stop exercising or forget arguments or conform to the dominant view. Existing research in this area tends to focus on how to design equitable, inclusive and fair deliberative procedures. However, the consensus paradox indicates why such ex ante measures may be insufficient. Ensuring deliberative rationality over time might require provisions in the ex post phase, too, empowering institutions or individuals to recurring contestation or to dissent from the consensus view. In micro settings, such measures may include devil's advocacy or dialectical inquiry (Schwenk 1990). At the macro level, institutional safeguards of rationality may include judicial review (Zurn 2007), monitoring and accountability agencies (Rosanvallon 2008), conscientious exemption (Ceva 2011), whistleblowing or civil disobedience. Thus, the consensus paradox points to the importance of integrating the epistemic benefits of such institutions into deliberative democratic theory.

\section{Conclusion}

This paper has explored a previously neglected theoretical puzzle at the heart of deliberative democratic theory: The possible conflict over time between consensus and rationality. In short, the more an agreement approaches the ideal of a rational consensus, the worse the conditions will be ex post for rational deliberation. While this paradox is demonstrable in deliberative theory, we have also suggested cognitive and social-psychological mechanisms - stagnation, forgetfulness and conformism - that may account for the paradox in practice. Moreover, this 
paper has served to open a research agenda for examining this puzzle empirically, that is, for studying whether consensus-like agreement actually decreases the rationality of future deliberation. Ideally, the paradox should be studied both under the controlled circumstances of small-group experiments and in the messier real-world public deliberative arenas where actual political agents make binding collective decisions. Finally, the paper has addressed the possibly dramatic implications for deliberative democratic theory of the tension between rationality and consensus, and discussed strategies by which to handle or resolve the dilemma. If disagreement produces better deliberative agreements, how could that deliberative productivity be sustained over time, once disagreement has been turned into a robust, rational agreement?

While the consensus paradox, as we have outlined it in this paper, sheds light on an underexplored conflict between fundamental values in deliberative democratic theory, it also addresses a long-standing concern in political thought that antedates the recent deliberative turn in democracy research (Aristotle 2009, bk. II:II; de Tocqueville 2006, bk. III:21; Mill 1991, 59): How to balance the good of robust, reasonable agreement against the bad of social conformism, or the good of continuous, open and public contestation against the bad of collective indecisiveness? Put differently, how to institutionalize public debate in democratic societies in order to promote rationality in public policy? The exercise of public power should be transparent and intelligible to citizens (Waldron 1987), a requirement of legitimacy that might be difficult to meet to the extent that broad agreements turn out to impede the rationality of public discourse over time. Hence, taking seriously the theoretical challenge of the consensus paradox will be pertinent for a broader tradition of democratic thought and practice.

\footnotetext{
${ }^{1}$ To illustrate: At time T, a group reaches an agreement constituted by the following conditional inference: 'if A, B, C, D, then Z'. Now, at time $\mathrm{T}+1$, they reach an agreement on another position in another issue, constituted by an inference which contains a negation of one of the premises in the former inference, e.g. 'since $\mathrm{X}$ and not-A, therefore $\mathrm{Y}$ '. The agreement on the first issue becomes less rational at $\mathrm{T}+1$ compared to $\mathrm{T}$, unless further deliberation takes place in
} 
order to revise the first inference in the light of the content of the second inference (cf. Gärdenfors 1992).

2 (Neuwirth, Frederick, and Mayo 2007; Priest 2006; Kim 2004; Noelle-Neumann 1993)

${ }^{3}$ (Coglianese 2003; Karpowitz and Mansbridge 2005; cf. Renz 2006; Schwenk and Valacich 1994; Vanlear and Mabry 1999)

${ }^{4}$ Cf. Nir (2011), who documents similar detrimental effects of consensus on participation.

${ }^{5}$ For applications in various fields, see e.g. (Jiménez-Aleixandre and Erduran 2007 (science education); Verheij 2003 (law); Bench-Capon and Dunne 2007 (artificial intelligence)) 


\section{References}

Aristotle. 2009. "Politics: A Treatise on Government." Translated by William Ellis. http://www.gutenberg.org/ebooks/6762.

Asch, S. 1951. "Effects of Group Pressure Upon the Modification and Distortion of Judgment." In Groups, Leadership and Men, edited by H Guetzkow. Pittsburgh: Carnegie Press.

Bench-Capon, T.J.M., and Paul E. Dunne. 2007. “Argumentation in Artificial Intelligence.” Artificial Intelligence 171 (10-15) (July): 619-641. doi:10.1016/j.artint.2007.05.001.

Benhabib, Seyla. 1994. "Deliberative Rationality and Models of Democratic Legitimacy." Constellations 1 (1): 26-52.

Blair, J. Anthony. 2012. Groundwork in the Theory of Argumentation. Springer.

Blau, Adrian. 2011. "Rationality and Deliberative Democracy: A Constructive Critique of John Dryzek's Democratic Theory." Contemporary Political Theory 10 (1) (February): 37-57. doi:10.1057/cpt.2010.3.

Bohman, James. 1996. Public Deliberation: Pluralism, Complexity, and Democracy. Cambridge, MA: The MIT Press.

. 1998. "The Coming of Age of Deliberative Democracy." The Journal of Political Philosophy 6 (4): 400-425.

—. 2003. "Reflexive Public Deliberation Democracy and the Limits of Pluralism." Philosophy \& Social Criticism 29 (1) (January 1): 85-105. doi:10.1177/0191453703029001835.

—. 2006. "Deliberative Democracy and the Epistemic Benefits of Diversity." Episteme 3 (03): 175-191. doi:10.3366/epi.2006.3.3.175.

Brady, John S. 2004. "No Contest? Assessing the Agonistic Critiques of Jürgen Habermas's Theory of the Public Sphere." Philosophy \& Social Criticism 30 (3) (May 1): 331-354. doi:10.1177/0191453704043096. 
Bächtiger, André, Simon Niemeyer, Michael Neblo, Marco R. Steenbergen, and Jurg Steiner. 2010. "Disentangling Diversity in Deliberative Democracy: Competing Theories, Their Blind Spots and Complementarities." Journal of Political Philosophy 18 (1): 32-63. doi:10.1111/j.1467-9760.2009.00342.x.

Bächtiger, André, Markus Spörndli, Marco R. Steenbergen, and Jurg Steiner. 2005. “The Deliberative Dimensions of Legislatures." Acta Politica 40 (2): 225-238. doi:10.1057/palgrave.ap.5500103.

Cappella, Joseph N., Vincent Price, and Lilach Nir. 2002. “Argument Repertoire as a Reliable and Valid Measure of Opinion Quality: Electronic Dialogue During Campaign 2000.” Political Communication 19 (1): 73-93. doi:10.1080/105846002317246498.

Ceva, Emanuela. 2011. "Self-legislation, Respect and the Reconciliation of Minority Claims." Journal of Applied Philosophy 28 (1) (February): 14-28. doi:10.1111/j.14685930.2010.00507.x.

Chambers, Simone. 2003. "Deliberative Democratic Theory." Annual Review of Political Science 6: 307-26.

Coglianese, Cary. 2003. "Does Consensus Work? A Pragmatic Approach to Public Participation in the Regulatory Process.” In Renascent Pragmatism: Studies in Law and Social Science, edited by Alfonso Morales. Hamsphire: Ashgate.

Cohen, Joshua. 1989. "Deliberation and Democratic Legitimacy." In The Good Polity, edited by Alan Hamlin and Philip Pettit. Oxford: Blackwell. 1998. "Democracy and Liberty.” In Deliberative Democracy, edited by Jon Elster, 1:185-231. Cambridge Studies in the Theory of Democracy. Cambridge: Cambridge University Press.

Cooke, Maeve. 2000. "Five Arguments for Deliberative Democracy." Political Studies 48 (5): 947-969. doi:10.1111/1467-9248.00289.

Deveaux, Monique. 2003. “A Deliberative Approach to Conflicts of Culture.” Political Theory 31 (6) (December): 780-807. doi:10.1177/0090591703256685. 
Doheny, Shane, and Claire O’Neill. 2010. “Becoming Deliberative Citizens: The Moral Learning Process of the Citizen Juror." Political Studies 58 (4) (October): 630-648. doi:10.1111/j.1467-9248.2009.00799.x.

Elstub, Stephen. 2010. “The Third Generation of Deliberative Democracy.” Political Studies Review 8 (3): 291-307. doi:10.1111/j.1478-9302.2010.00216.x.

Fishkin, James. 1997. The Voice of the People : Public Opinion and Democracy. New Haven: Yale University Press.

Gastil, John. 2006. “How Balanced Discussion Shapes Knowledge, Public Perceptions, and Attitudes: A Case Study of Deliberation on the Los Alamos National Laboratory." Journal of Public Deliberation 2 (1).

- 2010. The Group in Society. Los Angeles: SAGE Publications.

Gastil, John, and James Dillard. 1999. "Increasing Political Sophistication Through Public Deliberation.” Political Communication 16 (1) (February): 3-23. doi:10.1080/105846099198749.

Goodin, Robert E, and Simon J Niemeyer. 2003. "When Does Deliberation Begin? Internal Reflection Versus Public Discussion in Deliberative Democracy.” Political Studies 51 (4) (December 1): 627-649. doi:10.1111/j.0032-3217.2003.00450.x.

Goodin, Robert E. 2000. "Democratic Deliberation Within.” Philosophy \& Public Affairs 29 (1): 81-109.

Govier, Trudy. 1995. "Reply to Massey." In Fallacies: Classical and Contemporary Readings, edited by Hans V. Hansen. Penn State Press.

Grimes, Marcia. 2008. “The Civic Benefits of Imperfect Deliberation.” Journal of Public Deliberation 4 (1).

Groarke, Leo. 1996. “Logic, Art and Argument.” Informal Logic 18 (2) (January 1). http://www.phaenex.uwindsor.ca/ojs/leddy/index.php/informal_logic/article/view/2376. Gutmann, Amy, and Dennis Thompson. 2000. "Why Deliberative Democracy Is Different." Social Philosophy and Policy 17 (1): 161-180. doi:10.1017/S0265052500002570. 
Gutmann, Amy, and Dennis Frank Thompson. 1996. Democracy and Disagreement. Harvard University Press.

Gärdenfors, Peter. 1992. Belief Revision. Cambridge Tracts in Theoretical Computer Science, 0956-9103 ; 29. Cambridge: Cambridge Univ. Press.

Habermas, Jürgen. 1988. Legitimation Crisis. Cambridge UK: Polity Press.

1996. Between Facts and Norms: Contributions to a Discourse Theory of Law and Democracy. Cambridge, MA: MIT Press.

Hibbing, John, and Elizabeth Theiss-Morse. 2002. Stealth Democracy: Americans' Beliefs About How Government Should Work. Cambridge: Cambridge University Press. Jiménez-Aleixandre, María Pilar, and Sibel Erduran. 2007. “Argumentation in Science Education: An Overview." In Argumentation in Science Education, edited by Sibel Erduran and María Pilar Jiménez-Aleixandre, 3-27. Science \& Technology Education Library 35. Springer Netherlands. http://link.springer.com/chapter/10.1007/978-1-40206670-2_1.

Karpowitz, Christopher F., and Jane Mansbridge. 2005. "Disagreement and Consensus: The Need for Dynamic Updating in Public Deliberation.” Journal of Public Deliberation 1 (1): $348-364$.

Kerr, Norbert L., and R. Scott Tindale. 2004. "Group Performance and Decision Making.” Annual Review of Psychology 55 (1) (February): 623-655. doi:10.1146/annurev.psych.55.090902.142009.

Kim, S.-H. 2004. "Talking on 'Sunshine in North Korea': A Test of the Spiral of Silence as a Theory of Powerful Mass Media.” International Journal of Public Opinion Research 16 (1): 39-62. doi:10.1093/ijpor/16.1.39.

Larmore, C. 1990. "Political Liberalism.” Political Theory 18 (3) (August): 339-360. doi:10.1177/0090591790018003001.

Larsen, K. S. 1990. “The Asch Conformity Experiment: Replication and Transhistorical Comparisons." Journal of Social Behavior and Personality 58: 164-171. 
Lupia, Arthur. 2002. "Deliberation Disconnected: What It Takes to Improve Civic Competence." Law and Contemporary Problems 65 (3): 133-150.

Mackie, G. 2006. “Does Democratic Deliberation Change Minds?" Politics, Philosophy \& Economics 5 (3) (October): 279-303. doi:10.1177/1470594X06068301.

Mansbridge, Jane, James Bohman, Simone Chambers, David Estlund, Andreas Føllesdal, Archon Fung, Cristina Lafont, Bernard Manin, and José Luis Martí. 2010. “The Place of Self-Interest and the Role of Power in Deliberative Democracy*." Journal of Political Philosophy 18 (1) (March): 64-100. doi:10.1111/j.1467-9760.2009.00344.x.

Markell, Patchen. 1997. "Contesting Consensus: Rereading Habermas on the Public Sphere.” Constellations 3 (3): 377-400.

Mendelberg, Tali. 2002. “The Deliberative Citizen: Theory and Evidence.” Political Decision Making, Deliberation and Participation 6: 151-193.

Mill, John Stuart. 1991. “On Liberty.” In On Liberty and Other Essays. Oxford World's Classics. Oxford: Oxford University Press.

Moore, Alfred, and Kieran O’Doherty. 2012. "Deliberative Voting: Operationalizing Consensus in a Deliberative Minipublic.” SSRN eLibrary. http://ssrn.com/paper=2104573.

Mouffe, Chantal. 1995. "Democracy and Pluralism: A Critique of the Rationalist Approach." Cardozo Law Review 16 (5): 1533-1546.

. 2005. On the Political. London: Routledge.

Mutz, Diana C. 2008. "Is Deliberative Democracy a Falsifiable Theory?” Annual Review of Political Science 11 (1) (June): 521-538. doi:10.1146/annurev.polisci.11.081306.070308. Nanz, Patrizia, and Jens Steffek. 2005. "Assessing the Democratic Quality of Deliberation in International Governance: Criteria and Research Strategies.” Acta Politica 40 (3) (September): 368-383. doi:10.1057/palgrave.ap.5500118.

Neblo, Michael. 2007. "Family Disputes: Diversity in Defining and Measuring Deliberation." Swiss Political Science Review 13 (4): 527-57. 
Neuwirth, Kurt, Edward Frederick, and Charles Mayo. 2007. "The Spiral of Silence and Fear of Isolation." Journal of Communication 57 (3) (September): 450-468. doi:10.1111/j.14602466.2007.00352.x.

Niemeyer, Simon, and John S. Dryzek. 2007. "The Ends of Deliberation: Meta-consensus and Inter-subjective Rationality as Ideal Outcomes.” Swiss Political Science Review 13 (4): 497-526.

Nir, Lilach. 2011. "Disagreement and Opposition in Social Networks: Does Disagreement Discourage Turnout?” Political Studies 59 (3) (October 1): 674-692. doi:10.1111/j.14679248.2010.00873.x.

Noelle-Neumann, Elisabeth. 1993. The Spiral of Silence : Public Opinion, Our Social Skin. 2nd ed. Chicago: University of Chicago Press.

Pettit, Philip. 2001. "Deliberative Democracy and the Discursive Dilemma." Philosophical Issues 11: 268-299.

Pingree, Raymond J. 2006. "Decision Structure and the Problem of Scale in Deliberation." Communication Theory 16 (2): 198-222.

Pinto, Robert. 2001. Argument, Inference, and Dialectic : Collected Papers on Informal Logic. Dordrecht ;;Boston: Kluwer Academic.

Postmes, Tom, Russell Spears, and Sezgin Cihangir. 2001. "Quality of Decision Making and Group Norms.” Journal of Personality and Social Psychology 80: 918-930. doi:10.1037/0022-3514.80.6.918.

Price, Vincent, Joseph Cappella, and Lilach Nir. 2002. "Does Disagreement Contribute to More Deliberative Opinion?” Political Communication 19 (1) (January): 95-112. doi:10.1080/105846002317246506.

Priest, S. H. 2006. "Public Discourse and Scientific Controversy: A Spiral-of-Silence Analysis of Biotechnology Opinion in the United States.” Science Communication 28 (2) (December): 195-215. doi:10.1177/1075547006293918. 
Renz, Mary Ann. 2006. "Paving Consensus: Enacting, Challenging, and Revising the Consensus Process in a Cohousing Community." Journal of Applied Communication Research 34 (2) (May): 163-190. doi:10.1080/00909880600574088.

Risse, Thomas. 2004. "Global Governance and Communicative Action." Government and Opposition 39 (2): 288-313.

Rosanvallon, Pierre. 2008. Counter-democracy: Politics in an Age of Distrust. Cambridge: Cambridge University Press.

Ryfe, David M. 2005. “Does Deliberative Democracy Work?” Annual Review of Political Science 8: 49-71.

Sanders, Lynn M. 1997. “Against Deliberation.” Political Theory 25 (3): 347-376.

Schneider, Dana M., and Michael J. Watkins. 1996. "Response Conformity in Recognition Testing." Psychonomic Bulletin \& Review 3 (4): 481-485.

Schweiger, David M., William R. Sandberg, and James W. Ragan. 1986. “Group Approaches for Improving Strategic Decision Making: A Comparative Analysis of Dialectical Inquiry, Devil's Advocacy, and Consensus." Academy of Management Journal 29 (1): 51-71. Schwenk, Charles. 1990. "Effects of Devil's Advocacy and Dialectical Inquiry on Decision Making: A Meta-analysis.” Organizational Behavior and Human Decision Processes 47 (October): 161-176. doi:10.1016/0749-5978(90)90051-A.

Schwenk, Charles, and J. S. Valacich. 1994. "Effects of Devil's Advocacy and Dialectical Inquiry on Individuals Versus Groups." Organizational Behavior and Human Decision Processes 59 (2): 210-222.

Simon, Adam, and Michael Xenos. 2000. "Media Framing and Effective Public Deliberation." Political Communication 17 (4) (October): 363-376. doi:10.1080/10584600050178979. Steenbergen, Marco R., André Bächtiger, Markus Spörndli, and Jurg Steiner. 2003. "Measuring Political Deliberation: A Discourse Quality Index.” Comparative European Politics 1 (1) (March): 21-48. doi:10.1057/palgrave.cep.6110002. 
Steiner, Jürg, André Bächtiger, Markus Spörndli, and Marco R. Steenbergen. 2004. Deliberative Politics in Action: Analyzing Parliamentary Discourse. Cambridge: Cambridge University Press.

Sunstein, Cass. 2005. Why Societies Need Dissent. Cambridge, MA: Harvard University Press. Surowiecki, James. 2005. The Wisdom of Crowds. 1st Anchor books ed. New York: Anchor Books.

Thompson, Dennis. 2008. "Deliberative Democratic Theory and Empirical Political Science.” Annual Review of Political Science 11: 497-520.

de Tocqueville, Alexis. 2006. Democracy in America. Translated by Henry Reeve. Project Gutenberg. http://www.gutenberg.org/ebooks/815.

Tung, L. 1993. “The Effects of Dialectical Inquiry, Devil’s Advocacy, and Consensus Inquiry Methods in a GSS Environment.” Information \& Management 25 (July): 33-41. doi:10.1016/0378-7206(93)90023-M.

Valadez, Jorge. 2001. Deliberative Democracy: Political Legitimacy and Self-determination in Multicultural Societies. Westview Press.

Waldron, Jeremy. 1987. “Theoretical Foundations of Liberalism.” The Philosophical Quarterly 37 (147): $127-150$.

Walton, Douglas. 1996. Argumentation Schemes for Presumptive Reasoning. Routledge.

Vanlear, C. A., and E. A. Mabry. 1999. "Testing Contrasting Interaction Models for Discriminating Between Consensual and Dissentient Decision-Making Groups.” Small Group Research 30 (1) (February): 29-58. doi:10.1177/104649649903000103.

Verheij, Bart. 2003. "Dialectical Argumentation with Argumentation Schemes: An Approach to Legal Logic.” Artificial Intelligence and Law 11 (2-3) (June 1): 167-195. doi:10.1023/B:ARTI.0000046008.49443.36.

Wessler, Hartmut. 2008. "Investigating Deliberativeness Comparatively.” Political Communication 25 (1) (January): 1-22. doi:10.1080/10584600701807752. 
Young, Iris Marion. 2001. "Activist Challenges to Deliberative Democracy.” Political Theory 29 (5) (October): 670-690. doi:10.1177/0090591701029005004.

Zurn, Christopher. 2007. Deliberative Democracy and the Institutions of Judicial Review. Cambridge: Cambridge University Press. 